\title{
Effects of SuperUlam on Supporting Concentration and Mood: A Randomized, Double-Blind, Placebo-Controlled Crossover Study
}

\author{
Jay K Udani ${ }^{1,2}$ \\ ${ }^{1}$ Medicus Research, LLC, 18250 Roscoe Boulevard, Suite 240, Northridge, CA 91325, USA \\ ${ }^{2}$ Northridge Hospital Integrative Medicine Program, Northridge, CA 91325, USA \\ Correspondence should be addressed to Jay K Udani; jay.udani@medicusresearch.com
}

Received 16 July 2013; Accepted 4 October 2013

Academic Editor: Mani Vasudevan

Copyright (c) 2013 Jay K Udani. This is an open access article distributed under the Creative Commons Attribution License, which permits unrestricted use, distribution, and reproduction in any medium, provided the original work is properly cited.

\begin{abstract}
Background. SuperUlam is a proprietary blend of natural ingredients aimed at supporting brain health. We aimed to evaluate the effect of SuperUlam on attention and mood in healthy adults. Methods. Twenty healthy individuals aged 35-65 were enrolled in this randomized, double-blind, placebo-controlled, crossover study. Study duration was 3 weeks and consisted of 3 visits. Measurement of cognitive function included computer-based testing of reaction time, complex attention, working memory, sustained attention, and executive functioning. Mood testing was performed via the profile of mood states (POMS) survey and the Chalder fatigue scale. Results. Cognitive function testing demonstrated a significant improvement from baseline in executive functioning, cognitive flexibility, reaction time, and working memory in the product group only $(P<0.05)$. When comparing the study product to placebo, the data demonstrated a significant decrease in tension, depression, and anger $(P<0.05)$. There was no significant difference between the product and placebo in the other measures of mood, including vigor, fatigue, confusion, and total mood disturbance. No adverse events were reported. Conclusions. Supplementation with SuperUlam is safe to consume with potential benefits to cognitive function and mood.
\end{abstract}

\section{Introduction}

In the past several years, much attention has been paid to products aimed at increasing energy, attention, and concentration. Products such as energy drinks, herbal supplements, and teas are often marketed to healthy individuals who wish to improve their cognitive health. Although popular and readily available, these products are not without risks. While consumption of one serving by a healthy adult may prove no harm, adverse cardiovascular and neurologic effects have been reported [1]. This has led to an increasing interest by consumers for safe products that can acutely increase concentration and memory.

Ginkgo biloba is a tree leaf extract commonly used as a memory and concentration enhancement. It has been investigated extensively both in patients with dementia or cerebral insufficiency as well as in healthy adults [2-5]. Plant extracts such as sireh (Piper betle) are used traditionally as stimulants throughout Asia. The spice turmeric (Curcuma longa), commonly found in Asian curries, has been described to have antioxidant and has neuroprotective effects [6]. A recent study demonstrated that consumption of curryspiced foods was associated with increased Mini-Mental State Examination scores in healthy elderly individuals [6]. Pegaga (Centella asiatica, also known as gotu kola) and curry leaf (Murraya koenigii) have both been shown to have neuroprotective effects in laboratory research $[7,8]$. In Ayurvedic medicine, pegaga is known as a rejuvenating herb for nerve and brain cells and is thought to increase intelligence, longevity, and memory $[7,8]$. Both vitamin $\mathrm{C}$ and vitamin $\mathrm{E}$ have been reported to have potential benefits to cognitive function in elderly patients and those suffering from Alzheimer's disease $[9,10]$. Ulam raja (Cosmos caudatus) is an annual plant found in tropical regions and is traditionally used in Malaysian culture for antiaging and vascular health. Extracts from this plant have been found to be high in proanthocyanidins, which are a class of flavanols that have antioxidant properties [11]. 
SuperUlam is a proprietary product containing extracts of sireh (Piper betle), turmeric (Curcuma longa), pegaga (Centella asiatica), curry leaf (Murraya koenigii), selasih (Ocimum basilicum), kesum (Polygonum minus), ulam raja (Cosmos caudatus), and vitamins $\mathrm{C}$ and $\mathrm{E}$. We aim to evaluate the effects of this proprietary blend on areas of cognitive function and mood.

Cognitive testing is aimed at making quantitative assessments of cognitive capabilities and degree of high-level thinking. The CNS Vital Signs Systems is a computerized neurocognitive test battery comprised of seven tests: verbal memory, visual memory, finger tapping, symbol digit coding, the Stroop test, a test of shifting attention, and the continuous performance test. The results of the CNS Vital Signs System have been shown to be reliable and valid, compared with conventional neuropsychological tests upon which they are based [12].

There are a number of approaches toward testing of mood. POMS is a psychological rating scale used to assess transient, distinct mood states [13]. The moods included are tension, depression, anger, vigor, fatigue, confusion, and total mood disturbance. The Chalder fatigue scale is a self-rating measure for both physical and mental symptoms [14]. The scale consists of eight questions relating to physical symptoms and six questions relating to symptoms of mental fatigue. Items are scored in a Likert format, with response options ranging from "better than usual" to "much worse than usual." Lower scores are preferable.

This randomized, double-blind, placebo-controlled crossover study aims to evaluate the effects of SuperUlam on cognitive function and mood in healthy adult subjects.

\section{Methods}

2.1. Subject Population. The study protocol and material were approved by an Institutional Review Board (Copernicus Group IRB, Cary, NC) and all subjects provided written informed consent prior to participation. This study was conducted in accordance with Good Clinical Practice Guidelines and the ethical principles of the Declaration of Helsinki. Healthy volunteers were recruited from the general population by online recruiting, advertising, and available clinical trial databases. Recruitment and interventions were conducted at the StayWell Research study site located in Northridge, California. The inclusion and exclusion criteria are outlined in Table 1.

2.2. Study Products. The intervention product tested was SuperUlam (Biotropics; Selangor, Malaysia). The product ingredients are listed in Table 2. The placebo, dispensed in a sensory identical, opaque capsule, was a combination of microcrystalline cellulose, calcium phosphate, and other inactive components. Both the study product and placebo product were provided by the sponsor and both were GMP certified.

2.3. Study Design. This was a randomized, double-blind, placebo-controlled, crossover study. Simple randomization was prepared using a computer program based on the atmospheric noise method, and sequential assignment was used to determine group allocation. Group allocation was placed in individually numbered envelopes to maintain blinding of all individuals and study staff. Study subjects attended three visits, consisting of a screening visit followed by two visits where product is administered. Subjects were screened at visit 1 to determine study eligibility. This included detailed history and physical examination, questionnaires on alcohol use and compliance, POMS testing, and CNSVS testing. Prior to discharge, subjects were provided standardized food to consume prior to the next visit and instructed to fast for 10 hours and sleep between 4.5 and 5.5 hours the night before the next visit. Subjects were also asked to refrain from consuming caffeine 24 hours prior to baseline visit. On visit 2 , subjects were randomized to receive a single dose of either the SuperUlam product or placebo. Testing consisted of CNSVS testing, the Chalder fatigue scale, and POMS scoring. After baseline testing was completed, the subject consumed the study product in clinic, and testing was then repeated every hour for five hours. Standardized food was provided during this time. Between visit 2 and visit 3, subjects underwent a seven-day washout period of any related supplements or stimulants. Crossover of study product was performed at visit 3 , where subjects who had received placebo at visit 2 would receive product at visit 3 , and those who received product at visit 2 would receive placebo at visit 2 . Otherwise, previsit preparation and visit procedures were conducted in a manner identical to visit 2. Product was only consumed in clinic and no product was dispensed for home consumption.

2.4. Outcome Measures. The primary objective of this study was to assess the effects of the SuperUlam product compared to placebo on the ability to improve attention and memory. Endpoints included cognitive function measurements, which were assessed using the computer-based CNS Vital Signs System (CNSVSS) (Morrisville, NC). The secondary objective of this study was to assess the effects of the SuperUlam product compared to placebo on mood state which were measured by the POMS and the Chalder scales. Table 3 outlines the scoring system and definitions for the CNSVSS, POMS, and Chalder scales. The tertiary objective of this study was to evaluate the safety of SuperUlam. Safety endpoints included vital signs (temperature, blood pressure, pulse, and respiratory rate) and adverse event $(\mathrm{AE})$ reporting.

2.5. Statistical Analysis. Paired sample $t$-tests were used for within subject means comparisons and independent sample $t$-tests for between group comparisons (placebo versus active group). Statistical analyses were performed using SPSS Base System ver. 1.8 (IBM, Chicago IL, USA). $P$ values less than 0.05 were considered statistically significant.

\section{Results}

Twenty-four subjects were screened to take part in this study. Of these, 20 were randomized and all 20 completed the study (Figure 1). Compliance was $100 \%$ for both placebo and product. Demographic data for the study participants is outlined in Table 4. 
TABLE 1: Inclusion and exclusion criteria.

\begin{tabular}{ll}
\hline Inclusion criteria & Exclusion criteria \\
\hline Age between $35-65$ years & Active or history of substance or alcohol abuse \\
BMI between $18-30 \mathrm{~kg} / \mathrm{m}^{2}$ & History of major depression, bipolar disorder, or schizophrenia \\
POMS score $>15$ at screening & Use of medications of ADD or ADHD \\
CNSVS score $>6$ at screening & Smoking \\
& Caffeine intake of over four servings daily \\
& (roughly $300-400$ mg) \\
& Use of any drugs or dietary supplements that may affect memory or \\
& mental performance \\
& Pregnant or lactating \\
& Any medical condition which in the opinion of the investigator might \\
& interfere with the subject's participation in the trial \\
\hline
\end{tabular}

BMI: body mass index.

POMS: profile of mood states.

CNSVS: CNS vital signs.

TABLE 2: SuperUlam ingredients.

\begin{tabular}{lc}
\hline \multicolumn{2}{c}{ SuperUlam Capsule } \\
\hline Extracts \\
Sireh extract & $150 \mathrm{mg}$ \\
Turmeric extract & $50 \mathrm{mg}$ \\
Pegaga extract & $100 \mathrm{mg}$ \\
Curry leaf extract & $50 \mathrm{mg}$ \\
Selasih extract & $50 \mathrm{mg}$ \\
Kesum extract & $150 \mathrm{mg}$ \\
Ulam Raja extract & $25 \mathrm{mg}$ \\
Tocobeads & $25 \mathrm{mg}$ \\
Ascorbic Acid & $36 \mathrm{mg}$ \\
Vitamin E 50\% CWS/S & $8 \mathrm{mg}$ \\
\hline Other Ingredients & $194 \mathrm{mg}$ \\
Microcrystalline cellulose PH102 & $68 \mathrm{mg}$ \\
Calcium phosphate dibasic dihydrate & $25 \mathrm{mg}$ \\
Sodium starch glycolate & $37 \mathrm{mg}$ \\
Glyceryl behenate & $27 \mathrm{mg}$ \\
Colloidal silicon dioxide & $14.9 \mathrm{mg}$ \\
\hline Coating & $5 \mathrm{mg}$ \\
Hydroxypropylmethylcellulose & $0.56 \mathrm{mg}$ \\
Glycerin & $0.12 \mathrm{mg}$ \\
Chlorophyll, sodium copper complex & $8.9 \mathrm{mg}$ \\
Carnauba wax & \\
Titanium oxide & \\
\hline
\end{tabular}

Baseline values for CNS Vital Signs testing found no significant difference between product and placebo groups. A significant increase in executive functioning was noted at hour 1 in the SuperUlam group compared with the placebo group $(P=0.047)$ (Table 5). Otherwise, there was no significant difference in any of the other components of CNS Vital signs testing between product and placebo.

When comparing hour 5 to baseline, subjects receiving active study product demonstrated statistically significant improvement in cognitive flexibility $(P=0.048)$, reaction

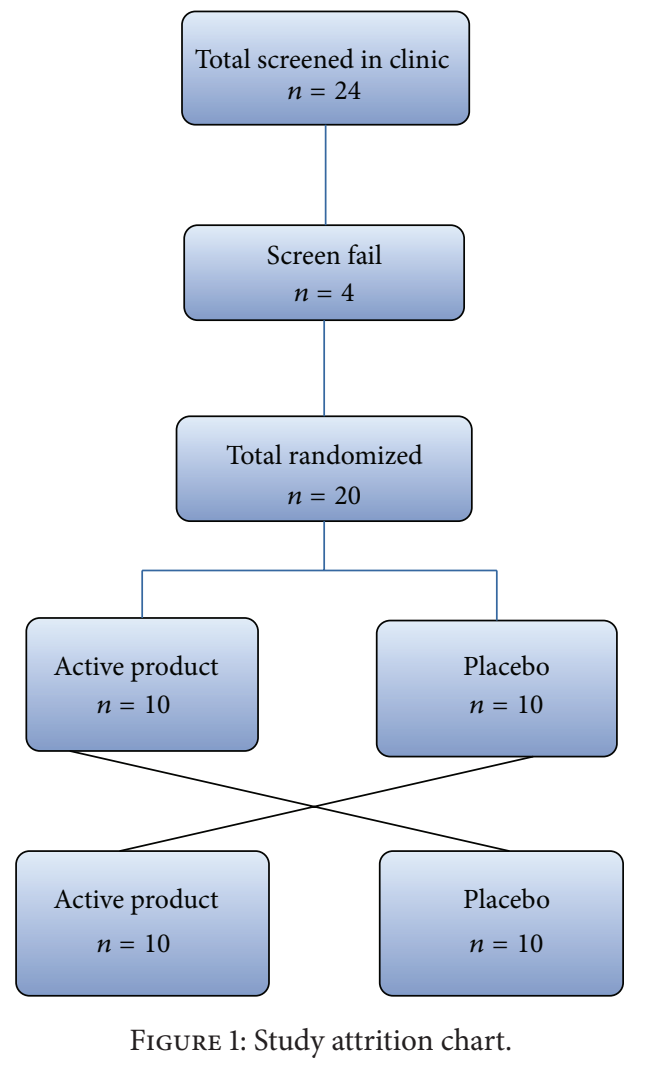

time $(P=0.01)$, working memory $(P<0.01)$, sustained attention $(P=0.048)$, and executive functioning $(P=0.042)$. Subject in the active group did show an increase in processing speed from baseline to hour $5(P<0.01)$, a higher speed meaning that the subject took longer to take the test. The overall composite score or the average standard score across all tests showed a statistically significant improvement from baseline to hour $5(P<0.001)$.

When comparing hour 5 to baseline, subjects receiving the placebo product demonstrated statistically significant worsening in reaction time $(P<0.01)$ and processing 
TABLE 3: Scoring system for CNSVSS, POMS, and Chalder scales.

\begin{tabular}{|c|c|c|c|}
\hline Scales and scoring & Definition & $\begin{array}{c}\text { Units and } \\
\text { normal range }\end{array}$ & Explanation \\
\hline \multicolumn{4}{|c|}{ CNS vital signs } \\
\hline Cognitive flexibility & Measure of frontal lobe functioning & $\begin{array}{l}\text { Milliseconds } \\
\text { Age-dependent }\end{array}$ & $\begin{array}{l}\text { A higher value represents a higher level of } \\
\text { functioning }\end{array}$ \\
\hline Reaction time & $\begin{array}{l}\text { Average measure of two distinct attention } \\
\text { components }\end{array}$ & $\begin{array}{l}\text { Milliseconds } \\
\text { Age-dependent }\end{array}$ & $\begin{array}{l}\text { A higher score represents a longer } \\
\text { reaction time }\end{array}$ \\
\hline Complex attention & $\begin{array}{l}\text { Combined measure of simple, choice, and } \\
\text { shifting attention elements }\end{array}$ & $\begin{array}{l}\text { Milliseconds } \\
\text { Age-dependent }\end{array}$ & $\begin{array}{l}\text { A higher score represents a higher level of } \\
\text { attention }\end{array}$ \\
\hline Working memory & $\begin{array}{l}\text { Measures well-known "2-back" working } \\
\text { memory }\end{array}$ & $\begin{array}{l}\text { Milliseconds } \\
\text { Age-dependent }\end{array}$ & $\begin{array}{l}\text { A higher score represents a higher level of } \\
\text { working memory }\end{array}$ \\
\hline Sustained attention & $\begin{array}{l}\text { Combined measure of three cascading } \\
\text { attention tests each slightly more difficult } \\
\text { than the previous. }\end{array}$ & $\begin{array}{l}\text { Milliseconds } \\
\text { Age-dependent }\end{array}$ & $\begin{array}{l}\text { A higher score represents a higher level of } \\
\text { sustained attention }\end{array}$ \\
\hline Executive functioning & $\begin{array}{l}\text { Measure of how well a subject deals with } \\
\text { making correct decisions in a shifting } \\
\text { rule and target environment }\end{array}$ & $\begin{array}{l}\text { Milliseconds } \\
\text { Age-dependent }\end{array}$ & $\begin{array}{l}\text { A higher score represents a higher level of } \\
\text { executive functioning }\end{array}$ \\
\hline Processing speed & $\begin{array}{l}\text { Scores how well a subject deals with } \\
\text { moving across a keyboard based on keys } \\
\text { and stimuli }\end{array}$ & $\begin{array}{l}\text { Milliseconds } \\
\text { Age-dependent }\end{array}$ & $\begin{array}{l}\text { A higher score represents a longer } \\
\text { processing speed }\end{array}$ \\
\hline Average standard score & $\begin{array}{l}\text { Composite score of overall cognitive } \\
\text { function }\end{array}$ & $\begin{array}{c}\text { Milliseconds } \\
\text { Age-dependent }\end{array}$ & $\begin{array}{l}\text { A higher score represents a higher level of } \\
\text { overall cognitive function }\end{array}$ \\
\hline \multicolumn{4}{|c|}{ POMS scoring } \\
\hline Tension & $\begin{array}{l}\text { Assess transient, distinct mood state of } \\
\text { tension }\end{array}$ & $\begin{array}{l}0-4 \text { Likert scale } \\
\text { No normal range }\end{array}$ & $\begin{array}{l}\text { A higher score indicates that subject } \\
\text { tends to be fidgety, restless, and quickly } \\
\text { frustrated with people }\end{array}$ \\
\hline Depression & $\begin{array}{l}\text { Assess transient, distinct mood state of } \\
\text { depression }\end{array}$ & $\begin{array}{l}0-4 \text { Likert scale } \\
\text { No normal range }\end{array}$ & $\begin{array}{l}\text { A higher score indicates that subject feels } \\
\text { complete and utter loss of hope and } \\
\text { unable to carry out normal activities }\end{array}$ \\
\hline Anger & $\begin{array}{l}\text { Assess transient, distinct mood state of } \\
\text { anger }\end{array}$ & $\begin{array}{l}0-4 \text { Likert scale } \\
\text { No normal range }\end{array}$ & $\begin{array}{l}\text { A higher score indicates the subject's } \\
\text { intensity of expressing anger at a } \\
\text { particular time }\end{array}$ \\
\hline Vigor & $\begin{array}{l}\text { Assess transient, distinct mood state of } \\
\text { vigor }\end{array}$ & $\begin{array}{l}0-4 \text { Likert scale } \\
\text { No normal range }\end{array}$ & $\begin{array}{l}\text { A higher score indicates that the subject } \\
\text { is feeling cheerful, lively, alert, active, and } \\
\text { carefree }\end{array}$ \\
\hline Fatigue & $\begin{array}{l}\text { Assess transient, distinct mood state of } \\
\text { fatigue }\end{array}$ & $\begin{array}{l}0-4 \text { Likert scale } \\
\text { No normal range }\end{array}$ & $\begin{array}{l}\text { A higher score indicates more severe } \\
\text { fatigue, fatigue distress, or impact on } \\
\text { activities of daily living }\end{array}$ \\
\hline Confusion & $\begin{array}{l}\text { Assess transient, distinct mood state of } \\
\text { confusion }\end{array}$ & $\begin{array}{l}0-4 \text { Likert scale } \\
\text { No normal range }\end{array}$ & $\begin{array}{l}\text { A higher score indicates that subject tends } \\
\text { to feel mixed up and confused either with } \\
\text { instructions or surrounding environment }\end{array}$ \\
\hline Total mood disturbance & $\begin{array}{l}\text { Composite score of distressed mood } \\
\text { states }\end{array}$ & $\begin{array}{l}0-4 \text { Likert scale } \\
\text { No normal range }\end{array}$ & $\begin{array}{l}\text { A higher score indicates anxiety, } \\
\text { emotional suppression, and psychological } \\
\text { distress }\end{array}$ \\
\hline \multicolumn{4}{|c|}{ Chalder scales } \\
\hline Total physical & $\begin{array}{l}\text { Self-rated 8-question scale of physical } \\
\text { symptoms }\end{array}$ & $\begin{array}{l}0-3 \text { Likert scale } \\
\text { No normal range }\end{array}$ & $\begin{array}{l}\text { High scores indicate an increased risk for } \\
\text { cardiovascular diseases }\end{array}$ \\
\hline Total mental & $\begin{array}{l}\text { Self-rated 6-question scale regarding } \\
\text { mental fatigue }\end{array}$ & $\begin{array}{l}0-3 \text { Likert scale } \\
\text { No normal range }\end{array}$ & $\begin{array}{l}\text { High scores indicate presence of anxiety } \\
\text { and depression }\end{array}$ \\
\hline
\end{tabular}

speed $(P=0.047)$. Additionally, a significant worsening in working memory among the placebo group was noted when comparing baseline to hours $1(P<0.01), 2(P<0.01)$, $3(P<0.01)$, and $4(P<0.01)$. Subjects in the placebo group demonstrated improvement from baseline to hour 5 in sustained attention $(P=0.02)$. There was no statistically significant change in the average standard score between baseline and hour 5 in the placebo group.

Of the components of the POMS score at hour 5, when compared to placebo, the active product group demonstrated a significant improvement in depression $(P<0.01)$ and anger $(P<0.001)$. Otherwise, there was no significant difference 
TABle 4: Demographic data.

\begin{tabular}{lcc}
\hline Baseline characteristics & Male & Female \\
\hline$N$ & 10 & 10 \\
Age (mean) & 47.7 & 47.6 \\
Age (range) & $36-65$ & $43-54$ \\
Weight in lbs (mean) & 193.1 & 155.3 \\
Weight in lbs (range) & $169-216$ & $120-190$ \\
BMI (mean) & 27.2 & 26.4 \\
BMI (range) & $25-30$ & $24-30$ \\
Menopausal \% & NA & $20 \%$ \\
Marital status & & \\
Single & 1 & 0 \\
Married & 7 & 8 \\
Divorced & 0 & 2 \\
Separated & 2 & 0 \\
Widowed & 0 & 0 \\
Domestic partner & 0 & 0 \\
Ethnicity & & \\
White & 3 & 0 \\
Asian & 0 & 0 \\
African-American & 1 & 0 \\
Hispanic/Latino & 6 & 0 \\
American Indian/Alaska Native & 0 & \\
Hawaiian/Pacific Islander & 0 & \\
Other & 0 & \\
\hline
\end{tabular}

in any of the other components of POMS scoring between product and placebo at hour 5 .

When comparing hour 5 to baseline, subjects receiving active study product demonstrated statistically significant improvement in tension $(P=0.02)$, depression $(P<0.001)$, anger $(P<0.001)$, vigor $(P<0.001)$, confusion $(P=0.03)$, and total mood disturbance $(P<0.001)$. Subjects receiving placebo demonstrated significant improvement in anger $(P<$ $0.001)$, vigor $(P<0.001)$, confusion $(P<0.001)$, and total mood disturbance $(P<0.001)$ (Table 6$)$.

There were no significant differences between groups at any time point for the total physical or total mental scores on the Chalder fatigue scale (Table 7). There were no serious or other adverse events reported in this study, and safety laboratory parameters were not investigated.

\section{Discussion}

Interest in products aimed at improving cognitive performance and mood is steadily increasing. Younger individuals are interested in products that allow them to both study longer and increase energy for social life. As pharmaceutical agents are often plagued with side effects [15], many individuals are in search of a natural option for improving cognitive functioning and mood. Products containing Ginkgo biloba and natural sources of caffeine such as tea and guarana have been investigated in clinical trials and are readily commercially available $[2-5,16,17]$. Other products, such as energy drinks, may not be well researched, may be costly, may require large amounts, or may contain caffeine or other stimulants.

SuperUlam is a proprietary mixture of vitamins $\mathrm{C}$ and $\mathrm{E}$ as well as extracts from plants shown in laboratory research or traditional use to improve concentration, mood, and/or energy. Extracts of sireh (Piper betle), turmeric (Curcuma longa), pegaga (Centella asiatica), curry leaf (Murraya koenigii), selasih (Ocimum basilicum), kesum (Polygonum minus), and ulam raja (Cosmos caudatus) are included. Although the potential mechanisms of action for cognitive and mood improvements of these agents are not completely clear, there is evidence of neuroprotective effects of turmeric (Curcuma longa) and its constituent curcuminoids [18-21], as well as vitamins $\mathrm{C}$ and $\mathrm{E}$ (tocotrienols and tocopherols) [22-29] in animal models. Tocotrienols have been shown to reduce tumor necrosis factor-alpha and interleukin-lbeta in brain regions of ethanol-treated animals [24]. A recent review described in vitro in cell culture studies that suggest the signal transduction mechanisms that may be involved in the neuroprotective effects of curcumin in turmeric (Curcuma longa) [30].

Centella asiatica is used traditionally in Ayurvedic and Chinese medicines as a brain tonic [7, 31-34]. The neuroprotective effects of Centella asiatica have been shown in various animal models [31, 32, 35], and the learning and memoryenhancing effects of a Centella asiatica extract were shown in a labyrinth test [36]. In an animal model, Centella asiatica also had antidepressant effects, reducing corticosterone levels and increasing levels of monoamine-related neurotransmitters [37].

Murraya koenigii (curry leaf extract) has also been shown to improve memory in animal models, perhaps by reducing cholinesterase activity $[8,38]$. Ocimum basilicum has been traditionally used to support neuroprotection. An animal model has shown that extracts of Ocimum basilicum extract can improve memory and also have antioxidant effects [39]. Other constituents of SuperUlam with known antioxidant potential include Polygonum minus (kesum) [40], Cosmos caudatus (ulam raja), traditionally used to improve blood circulation, [11] and vitamins $\mathrm{C}$ and $\mathrm{E}[23,25,26,41]$.

While this the first published human trial demonstrating the safety and efficacy of the proprietary SuperUlam product, evidence from other clinical trials demonstrates the effects of many of the individual ingredients found in SuperUlam. Early clinical evidence suggests improvement in cognitive function associated with Centella asiatica [42]. More recently, an aqueous extract of Centella asiatica standardized to constituent tannic acids, as well as asiaticoside and asiatic acid, improved cognitive performance in healthy men and women $[43,44]$ and in elderly subjects with mild cognitive impairment $[45,46]$.

In this study, SuperUlam was investigated for its ability to improve concentration and mood in healthy adults aged 35-65 years. Significant improvements were noted in multiple aspects of cognitive function and mood state. Of note, the data did demonstrate a worsening in processing speed in both active and placebo groups. We attribute this to fatigue related to performing the testing itself. This is of interest given that these subjects were all partially sleep deprived and 


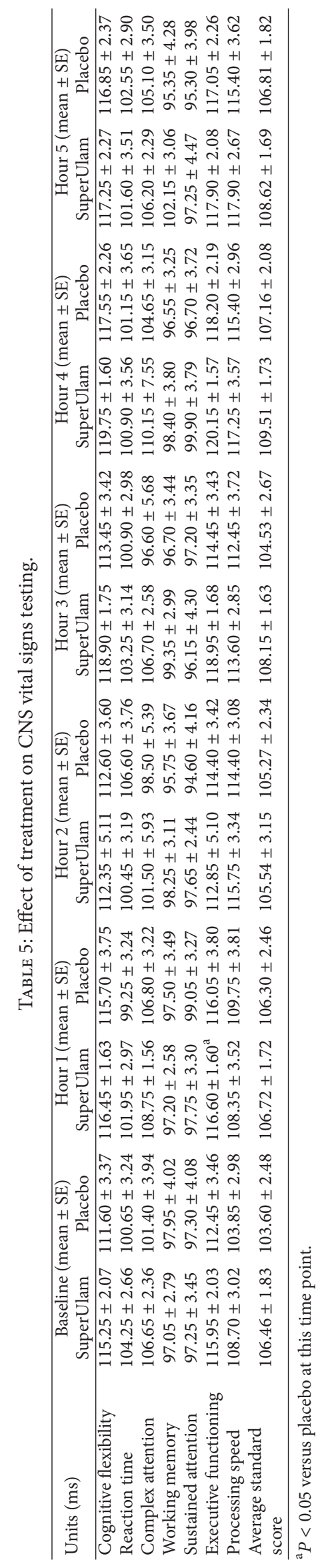




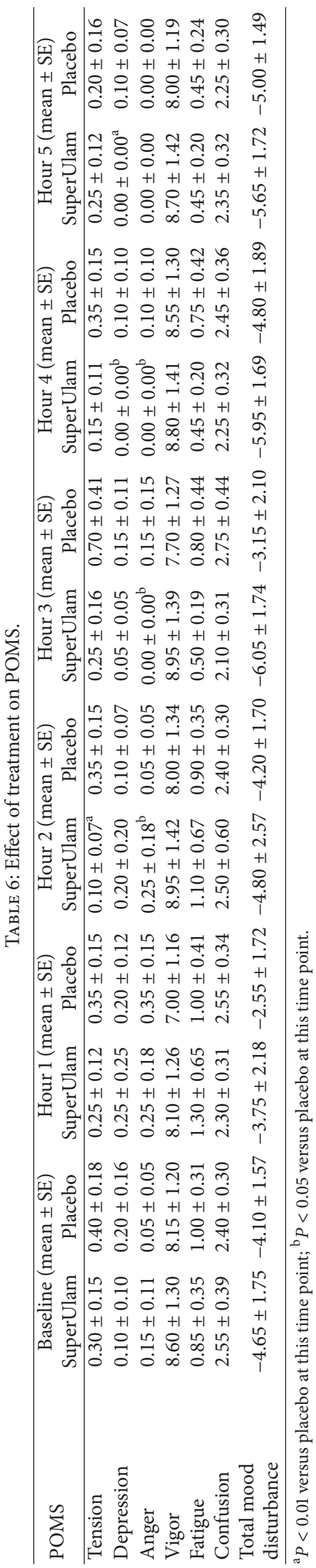




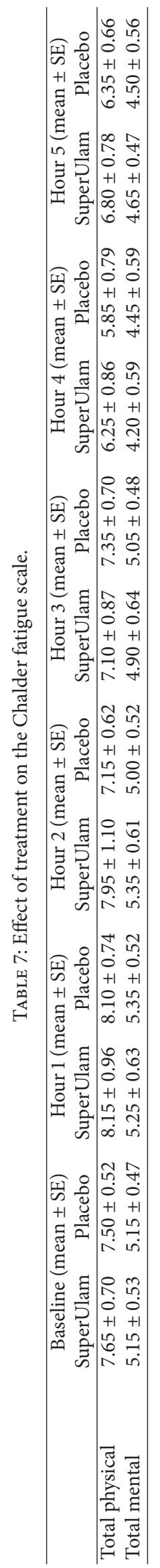


had already experienced hours of testing. A loss of vigor and increased confusion would be expected at this stage. A reduction in confusion at this stage may be related to a higher level of mental clarity. Overall, the results suggest that SuperUlam improved concentration earlier in the study (approximately hours 1-2) and mood later in the study (hours $3-5)$ in healthy adults.

In conclusion, the SuperUlam product appears to have a neurostimulatory and neurocognitive performance enhancement effect, impacting various aspects of cognition and memory at different times between one and five hours after a single dose. The product also appears to induce a state of relaxation as evidenced by reductions in tension, anger, and depression between hour four and five after dosing. The results of this study suggest that this product may be of interest to generally healthy middle-aged adults.

We attribute the lack of statistical significance in our study to small sample size. A future higher-powered study is needed to investigate an appropriate number of individuals to generate further statistically significant results. Further animal and in vitro studies are needed in order to fully determine the mechanism of action. Pharmacokinetic and pharmacodynamic testing may be required to understand the dissolution, absorption, and activity characteristics of this product. There is also need for investigation in older individuals and young adults, as well as in adults using medications or with disorders that may increase the risk of cognitive impairment.

\section{Acknowledgments}

Medicus Research would like to thank Biotropics Malaysia Berhad for supporting this clinical trial and providing the treatment and placebo products. This study was conducted under the sponsorship of Biotropics Malaysia Berhad. The study design and protocol writing were a collaborative effort between Biotropics Malaysia Berhad and Medicus Research LLC; the Contract Research Organization (CRO) was chosen to run the clinical operations of this study. Medicus Research has ongoing research support grants from Biotropics Malaysia (Berhad, Malaysia). Jay K Udani has provided consulting services to Biotropics. Medicus Research does not endorse any brand or product.

\section{References}

[1] J. P. Higgins, T. D. Tuttle, and C. L. Higgins, "Energy beverages: content and safety," Mayo Clinic Proceedings, vol. 85, no. 11, pp. 1033-1041, 2010.

[2] G. Bornhöft, S. Maxion-Bergemann, and P. F. Matthiessen, "External validity of clinical trials for treatment of dementia with Ginkgo biloba extracts," Zeitschrift fur Gerontologie und Geriatrie, vol. 41, no. 4, pp. 298-312, 2008.

[3] J. Birks and J. G. Evans, "Ginkgo biloba for cognitive impairment and dementia," Cochrane Database of Systematic Reviews, no. 2, Article ID CD003120, 2007.

[4] J. Kleijnen and P. Knipschild, "Ginkgo biloba for cerebral insufficiency," British Journal of Clinical Pharmacology, vol. 34, no. 4, pp. 352-358, 1992.
[5] P. R. Solomon, F. Adams, A. Silver, J. Zimmer, and R. Deveaux, "Ginkgo for memory enhancement: a randomized controlled trial," The Journal of the American Medical Association, vol. 288, no. 7, pp. 835-840, 2002.

[6] T.-P. Ng, P.-C. Chiam, T. Lee, H.-C. Chua, L. Lim, and E.-H. Kua, "Curry consumption and cognitive function in the elderly," The American Journal of Epidemiology, vol. 164, no. 9, pp. 898-906, 2006.

[7] M. Ramanathan, S. Sivakumar, P. R. Anandvijayakumar, C. Saravanababu, and P. R. Pandian, "Neuroprotective evaluation of standardized extract of Centella asciatica in monosodium glutamate treated rats," Indian Journal of Experimental Biology, vol. 45, no. 5, pp. 425-431, 2007.

[8] V. Mani, K. Ramasamy, A. Ahmad, M. Parle, S. A. A. Shah, and A. B. A. Majeed, "Protective effects of total alkaloidal extract from Murraya koenigii leaves on experimentally induced dementia," Food and Chemical Toxicology, vol. 50, no. 3-4, pp. 1036-1044, 2012.

[9] L. A. Boothby and P. L. Doering, "Vitamin C vitamin E for Alzheimer's disease," Annals of Pharmacotherapy, vol. 39, no. 12, pp. 2073-2080, 2005.

[10] K. H. Masaki, K. G. Losonczy, G. Izmirlian et al., "Association of vitamin $\mathrm{E}$ and $\mathrm{C}$ supplement use with cognitive function and dementia in elderly men," Neurology, vol. 54, no. 6, pp. 1265$1272,2000$.

[11] G. Shui, L. P. Leong, and S. P. Wong, "Rapid screening and characterisation of antioxidants of Cosmos caudatus using liquid chromatography coupled with mass spectrometry," Journal of Chromatography B, vol. 827, no. 1, pp. 127-138, 2005.

[12] C. T. Gualtieri and L. G. Johnson, "Reliability and validity of a computerized neurocognitive test battery, CNS vital signs," Archives of Clinical Neuropsychology, vol. 21, no. 7, pp. 623-643, 2006.

[13] D. McNair, M. Lorr, and L. Droppleman, Profile of Mood States (POMS), Multi-Health Systems, 1992.

[14] T. Chalder, G. Berelowitz, T. Pawlikowska et al., "Development of a fatigue scale," Journal of Psychosomatic Research, vol. 37, no. 2, pp. 147-153, 1993.

[15] M. Husain and M. A. Mehta, "Cognitive enhancement by drugs in health and disease," Trends in Cognitive Sciences, vol. 15, no. 1, pp. 28-36, 2011.

[16] E. J. Gardner, C. H. Ruxton, and A. R. Leeds, "Black tea-helpful or harmful? A review of the evidence," European Journal of Clinical Nutrition, vol. 61, no. 1, pp. 3-18, 2007.

[17] D. O. Kennedy, C. F. Haskell, K. A. Wesnes, and A. B. Scholey, "Improved cognitive performance in human volunteers following administration of guarana (Paullinia cupana) extract: comparison and interaction with Panax ginseng," Pharmacology Biochemistry and Behavior, vol. 79, no. 3, pp. 401-411, 2004.

[18] R. B. Mythri, J. Veena, G. Harish, B. S. Shankaranarayana Rao, and M. M. S. Bharath, "Chronic dietary supplementation with turmeric protects against 1-methyl-4-phenyl-1,2,3,6-tetrahydropyridine-mediated neurotoxicity in vivo: implications for Parkinson's disease," British Journal of Nutrition, vol. 106, no. 1, pp. 63-72, 2011.

[19] E. H. Ali and N. M. Arafa, "Comparative protective action of curcumin, memantine and diclofenac against scopolamineinduced memory dysfunction," Fitoterapia, vol. 82, no. 4, pp. 601-608, 2011

[20] A. Matteucci, R. Cammarota, S. Paradisi et al., "Curcumin protects against NMDA-induced toxicity: a possible role for NR2A 
subunit," Investigative Ophthalmology and Visual Science, vol. 52, no. 2, pp. 1070-1077, 2011.

[21] L.-F. He, H.-J. Chen, L.-H. Qian, G.-Y. Chen, and J. S. Buzby, "Curcumin protects pre-oligodendrocytes from activated microglia in vitro and in vivo," Brain Research, vol. 1339, pp. 60-69, 2010.

[22] L. B. Murad, M. R. Guimarães, and L. M. Vianna, "Alphatocopherol protects against memory impairment caused by LNAME and modulates the injury marker and blood coagulant parameters," BioFactors, vol. 37, no. 4, pp. 315-322, 2011.

[23] A. Wu, Z. Ying, and F. Gomez-Pinilla, "Vitamin e protects against oxidative damage and learning disability after mild traumatic brain injury in rats," Neurorehabilitation and Neural Repair, vol. 24, no. 3, pp. 290-298, 2010.

[24] V. Tiwari, A. Kuhad, and K. Chopra, "Suppression of neuroinflammatory signaling cascade by tocotrienol can prevent chronic alcohol-induced cognitive dysfunction in rats," Behavioural Brain Research, vol. 203, no. 2, pp. 296-303, 2009.

[25] V. Tiwari, A. Kuhad, M. Bishnoi, and K. Chopra, "Chronic treatment with tocotrienol, an isoform of vitamin E, prevents intracerebroventricular streptozotocin-induced cognitive impairment and oxidative-nitrosative stress in rats," Pharmacology Biochemistry and Behavior, vol. 93, no. 2, pp. 183-189, 2009.

[26] D. Delwing, C. S. Bavaresco, S. C. Monteiro, C. Matté, C. A. Netto, and A. T. S. Wyse, " $\alpha$-Tocopherol and ascorbic acid prevent memory deficits provoked by chronic hyperprolinemia in rats," Behavioural Brain Research, vol. 168, no. 2, pp. 185-189, 2006.

[27] S. C. Monteiro, C. Matté, C. S. Bavaresco, C. A. Netto, and A. T. S. Wyse, "Vitamins E and C pretreatment prevents ovariectomyinduced memory deficits in water maze," Neurobiology of Learning and Memory, vol. 84, no. 3, pp. 192-199, 2005.

[28] S. F. Ambali, S. B. Idris, C. Onukak, M. Shittu, and J. O. Ayo, "Ameliorative effects of vitamin $\mathrm{C}$ on short-term sensorimotor and cognitive changes induced by acute chlorpyrifos exposure in Wistar rats," Toxicology and Industrial Health, vol. 26, no. 9, pp. 547-558, 2010.

[29] P. Hasanein and S. Shahidi, "Effects of combined treatment with vitamins $\mathrm{C}$ and $\mathrm{E}$ on passive avoidance learning and memory in diabetic rats," Neurobiology of Learning and Memory, vol. 93, no. 4, pp. 472-478, 2010.

[30] G. M. Cole, B. Teter, and S. A. Frautschy, "Neuroprotective effects of curcumin," Advances in Experimental Medicine and Biology, vol. 595, pp. 197-212, 2007.

[31] M. H. V. Kumar and Y. K. Gupta, "Effect of Centella asiatica on cognition and oxidative stress in an intracerebroventricular streptozotocin model of Alzheimer's disease in rats," Clinical and Experimental Pharmacology and Physiology, vol. 30, no. 5-6, pp. 336-342, 2003.

[32] Y. K. Gupta, M. H. V. Kumar, and A. K. Srivastava, "Effect of Centella asiatica on pentylenetetrazole-induced kindling, cognition and oxidative stress in rats," Pharmacology Biochemistry and Behavior, vol. 74, no. 3, pp. 579-585, 2003.

[33] S. J. Flora and R. Gupta, "Beneficial effects of Centella asiatica aqueous extract against arsenic-induced oxidative stress and essential metal status in rats," Phytotherapy Research, vol. 21, no. 10, pp. 980-988, 2007.

[34] I. E. Orhan, "Centella asiatica (L.) urban: from traditional medicine to modern medicine with neuroprotective potential," Evidence-Based Complementary and Alternative Medicine, vol. 2012, Article ID 946259, 8 pages, 2012.
[35] M. H. V. Kumar and Y. K. Gupta, "Effect of different extracts of Centella asiatica on cognition and markers of oxidative stress in rats," Journal of Ethnopharmacology, vol. 79, no. 2, pp. 253-260, 2002.

[36] S. B. Rao, M. Chetana, and P. U. Devi, "Centella asiatica treatment during postnatal period enhances learning and memory in mice," Physiology and Behavior, vol. 86, no. 4, pp. 449-457, 2005.

[37] Y. Chen, T. Han, Y. Rui, M. Yin, L. Qin, and H. Zheng, "Effects of total triterpenes of Centella asiatica on the corticosterone levels in serum and contents of monoamine in depression rat brain," Journal of Chinese Medicinal Materials, vol. 28, no. 6, pp. 492496, 2005.

[38] M. Vasudevan and M. Parle, "Antiamnesic potential of Murraya koenigii leaves," Phytotherapy Research, vol. 23, no. 3, pp. 308316, 2009.

[39] K. S. Bora, S. Arora, and R. Shri, "Role of Ocimum basilicum L. in prevention of ischemia and reperfusion-induced cerebral damage, and motor dysfunctions in mice brain," Journal of Ethnopharmacology, vol. 137, no. 3, pp. 1360-1365, 2011.

[40] S. W. Qader, M. A. Abdulla, L. S. Chua, N. Najim, M. M. Zain, and S. Hamdan, "Antioxidant, total phenolic content and cytotoxicity evaluation of selected Malaysian plants," Molecules, vol. 16, no. 4, pp. 3433-3443, 2011.

[41] F. E. Harrison, J. Allard, R. Bixler et al., "Antioxidants and cognitive training interact to affect oxidative stress and memory in APP/PSEN1 mice," Nutritional Neuroscience, vol. 12, no. 5, pp. 203-218, 2009.

[42] M. V. R. A. Rao, K. Srinivasan, and T. K. Rao, "The effect of Centella asiatica on the general mental ability of mentally retarded children," Indian Journal of Psychiatry, vol. 19, no. 4, pp. 54-59, 1977.

[43] J. Wattanathorn, L. Mator, S. Muchimapura et al., "Positive modulation of cognition and mood in the healthy elderly volunteer following the administration of Centella asiatica," Journal of Ethnopharmacology, vol. 116, no. 2, pp. 325-332, 2008.

[44] R. D. O. Dev, S. Mohamed, Z. Hambali, and B. A. Samah, "Comparison on cognitive effects of Centella asiatica in healthy middle age female and male volunteers," European Journal of Scientific Research, vol. 31, no. 4, pp. 553-565, 2009.

[45] S. Tiwari, S. Singh, K. Patwardhan et al., "Effect of Centella asiatica on mild cognitive impairment (MCI) and other common age-related clinical problems," Digest Journal of Nanomaterials and Biostructures, vol. 3, pp. 215-220, 2008.

[46] J. J. Carlson, J. W. Farquhar, E. DiNucci et al., "Safety and efficacy of a Ginkgo biloba-containing dietary supplement on cognitive function, quality of life, and platelet function in healthy, cognitively intact older adults," Journal of the American Dietetic Association, vol. 107, no. 3, pp. 422-432, 2007. 


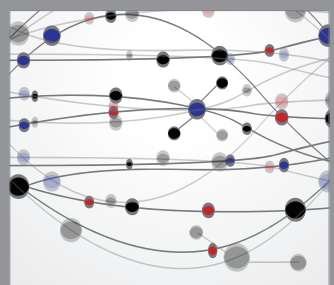

The Scientific World Journal
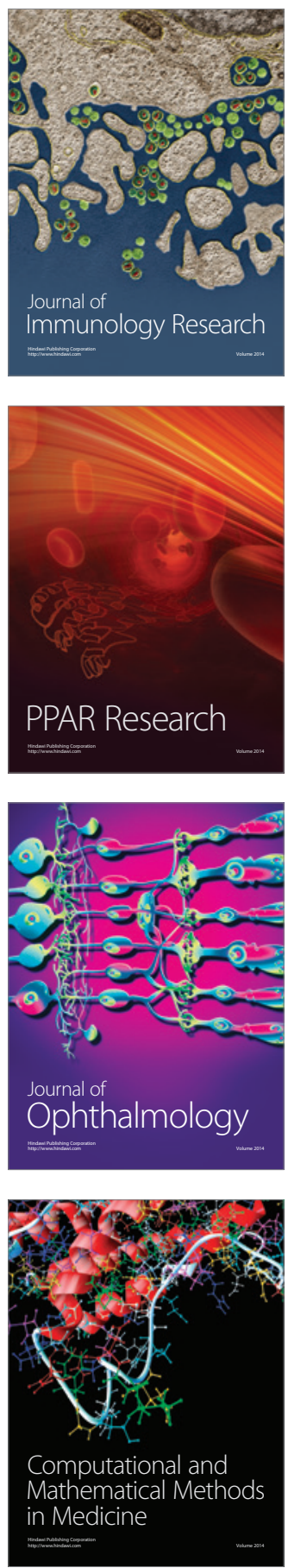

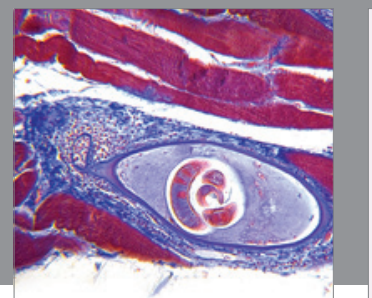

Gastroenterology

Research and Practice
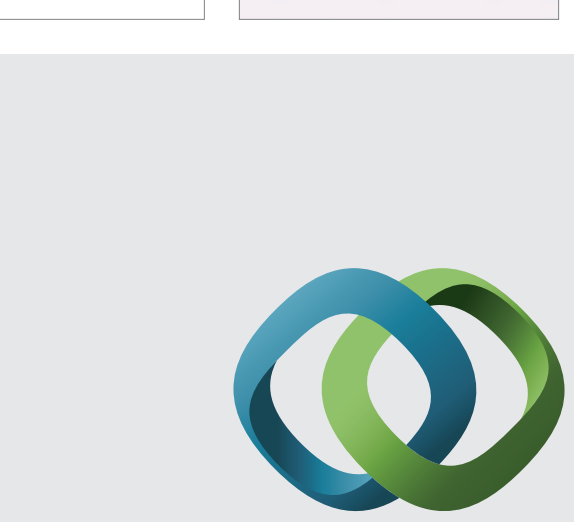

\section{Hindawi}

Submit your manuscripts at

http://www.hindawi.com
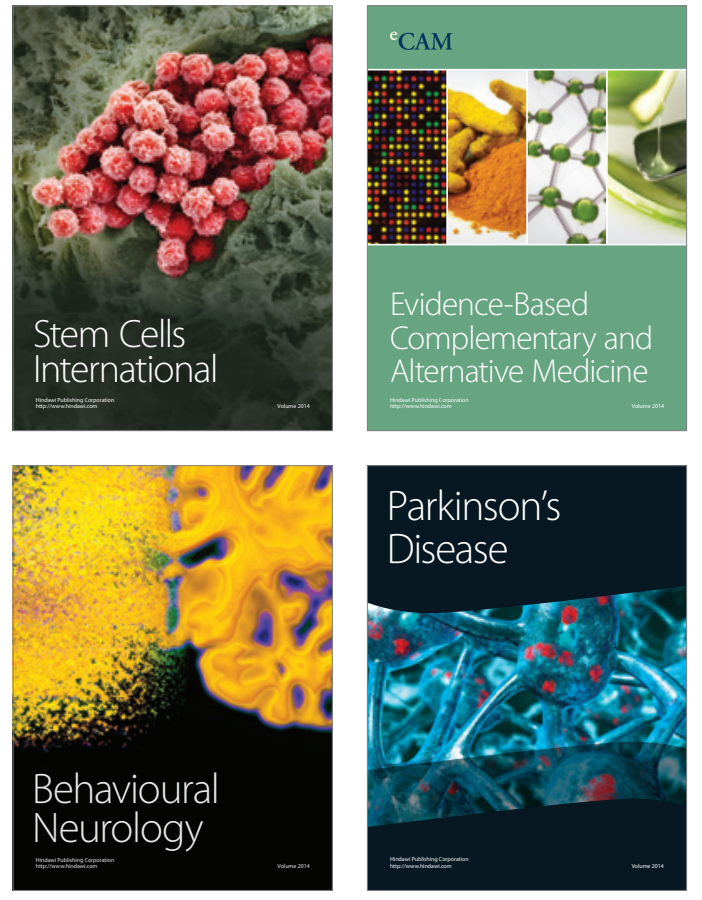
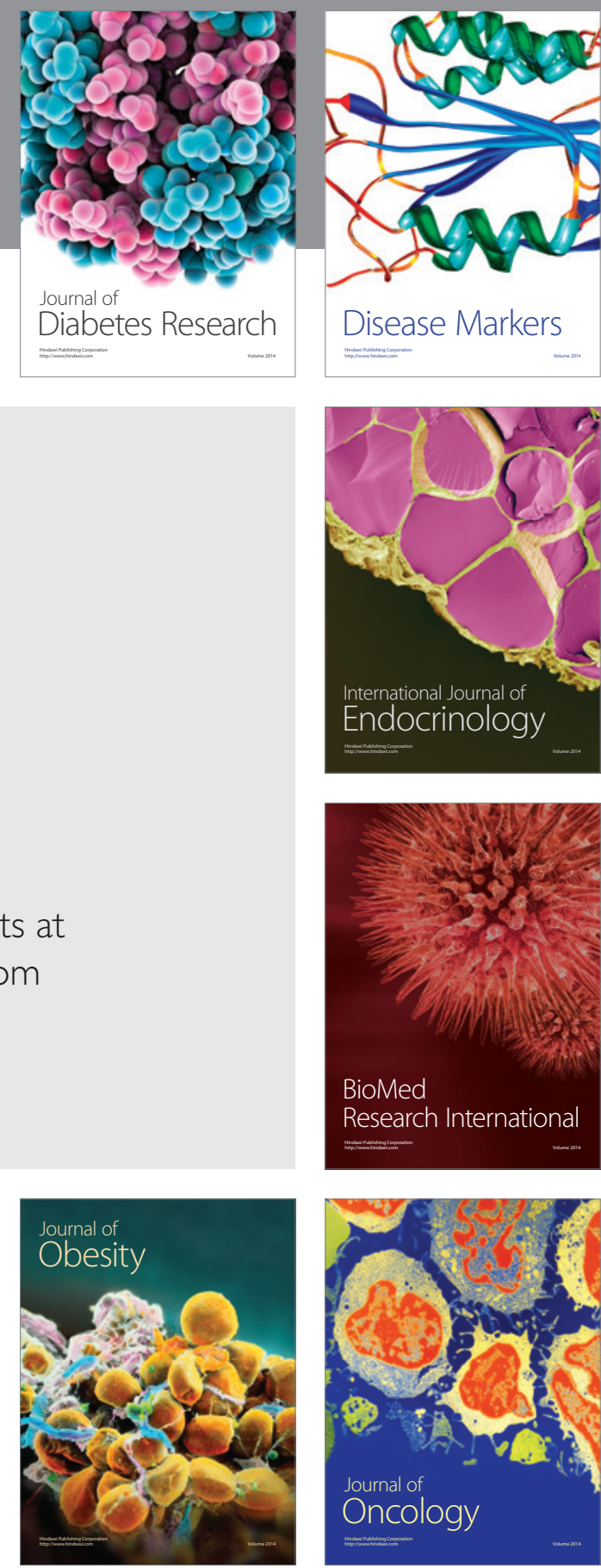

Disease Markers
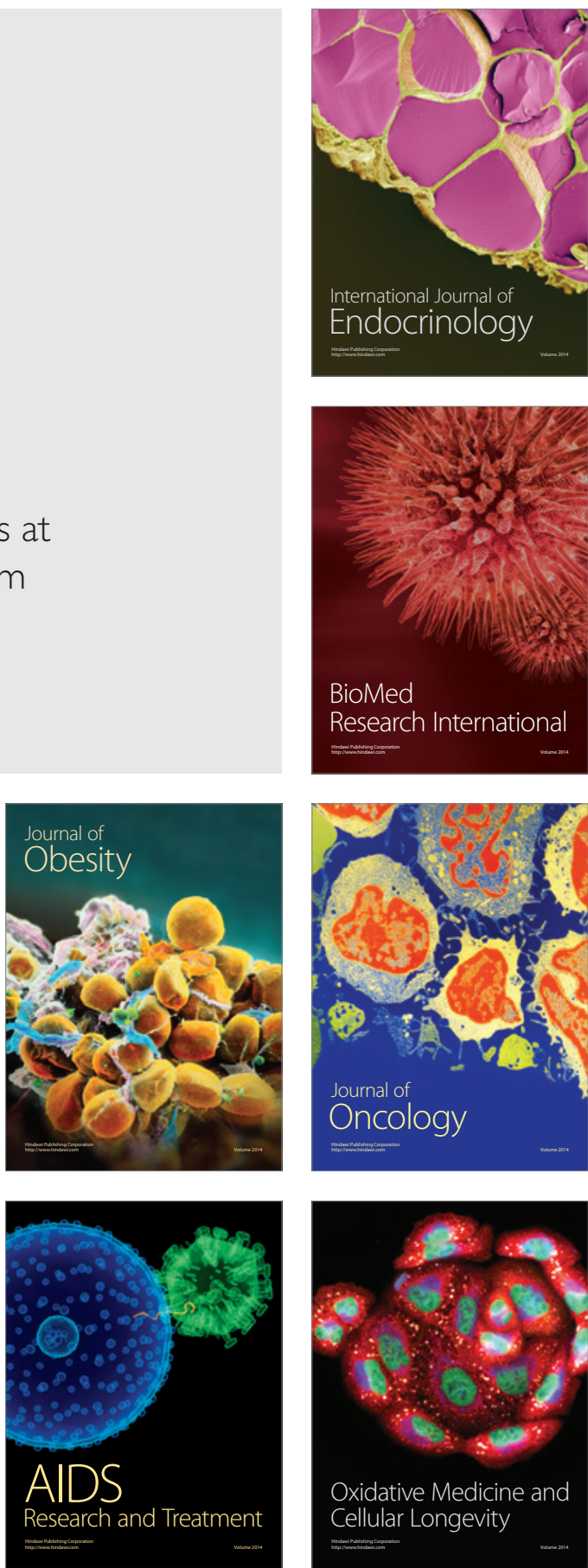